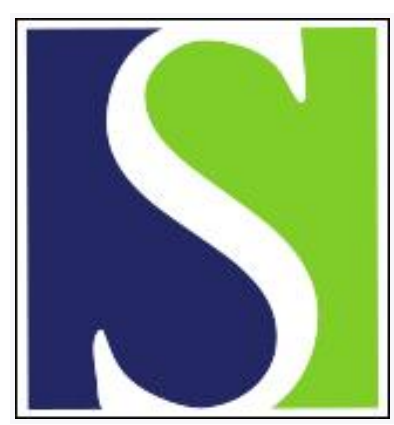

Scand J Work Environ Health 1988;14(1):49-51

https://doi.org/10.5271/sjweh.1957

Issue date: Feb 1988

Absence of mutagenic response to radiation from a video display terminal.

by Berg M, Lindelof B, Langlet I, Victorin K

Affiliation: Department of Dermatology, Karolinska Hospital, Stockholm, Sweden.

This article in PubMed: www.ncbi.nlm.nih.gov/pubmed/3281248

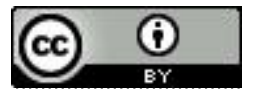




\title{
Absence of mutagenic response to radiation from a video display terminal
}

\author{
by Mats Berg, MD, ${ }^{1}$ Bernt Lindelöf, MD, ${ }^{1}$ Ingvar Langlet, MSc, ${ }^{2}$ Katarina Victorin, $\mathrm{MSc}^{3}$
}

\begin{abstract}
BERG M, LINDELÖF B, LANGLET I, VICTORIN K. Absence of mutagenic response to radiation from a video display terminal. Scand J Work Environ Health 14 (1988) 49-51. The standard Ames Salmonella test (TA 100) was used to detect the mutagenicity of radiation from a video display terminal. The Ames test is a sensitive assay that detects the ability of a chemical to damage deoxyribonucleic acid. It has also been employed to detect the mutagenicity of electromagnetic radiation. An extremely short distance $(62 \mathrm{~mm})$ from a video display terminal and an extremely high electrostatic field strength $(250 \mathrm{kv} / \mathrm{m})$ was employed. No mutagenic response was found in this test system.
\end{abstract}

Key terms: Ames test, electrostatic field strength, mutagenicity, skin diseases, visual display terminal.

Skin problems among people working at a video display terminal (VDT) were first reported from Norway in 1981 (10). Since then cases and such problems have been published in Great Britain (14), the United States $(4,5,11)$, and Sweden $(2,7,8,15)$. Most them have been Rosacea-like.

Several attempts have been made to establish a reasonable etiology for rashes possibly related to exposure to video display terminals. Studies have shown that, besides the desired visible radiation from the pattern generated on the screen, the radiation at shorter optical wavelengths is negligible and no ionizing radiation occurs (13). The physical effects generated by the terminals consist mainly of alternating magnetic field strengths that leak from the magnetic defection of the electron ray generating the screen pattern and an electrostatic field strength from a positively charged translucent film inside the front glass of the display. The field strength accelerates the negatively charged electrons towards the screen. No biological effects of the magnetic field strengths have been proved. The electrostatic field strength, on the other hand, seems to be a reasonable cause of skin rashes $(2,3,8,10)$.

However, in the popular press in Sweden there has been debate on whether work with video display terminals could cause severe side effects such as teratogenic effects and aging of the skin. Many pregnant women do not dare work at a terminal, and many operators are anxious about the possibility of skin deterioration. For this reason it was considered desirable to study the possible mutagenic effect of

\footnotetext{
' Department of Dermatology, Karolinska Hospital, Stockholm, Sweden.

2 National Institute of Radiation Protection, Stockholm, Sweden.

3 National Institute of Environmental Medicine, Stockholm, Sweden.
}

Reprint requests to: Dr M Berg, Department of Dermatology, Karolinska Hospital, S-104 01 Stockholm, Sweden. video display terminals in the Ames test using the Salmonella tester strain TA 100 . This is a sensitive assay for detecting the ability of a chemical to damage deoxyribonucleic acid (1). This test system has also previously been shown to detect mutagenic effects of electromagnetic radiation (9), such as ultraviolet radiation type $\mathrm{A}(9)$, ultraviolet radiation type $\mathrm{B}(12)$, $250-\mathrm{kV} X$ rays, and Cobalt-60 gamma rays (6).

\section{Materials and methods}

Salmonella typhimurium strain TA 100 was obtained from Dr Bruce Ames (University of California, Berkeley, California, United States). This bacterial tester strain mainly detects mutagens causing base-pair substitutions. It lacks the uvrB excision repair system. This bacterial strain is regularly used in the laboratory and was checked for proper genetic characteristics. Rat liver homogenate for metabolic activation was not used in this experiment. The mutagenic compound 2-nitrofluorene was used as a positive control. Two milliliters of soft agar containing traces of biotin and histidine was mixed with $0.1 \mathrm{ml}$ of an overnight $(14 \mathrm{~h}$ ) bacterial culture and poured onto minimal glucose agar plates (20 ml agar in petri dishes with a diameter of $90 \mathrm{~mm}$ ) (1). Thus the thickness of the agar layer containing the bacterial strain became approximately $0.3 \mathrm{~mm}$, which corresponds well to the thickness of the epidermis.

A common monochromatic video display terminal, (DM-14, manufactured by the Advanced Datum Information Corporation in Taiwan) was used in the experiments. In this type of terminal no attempts to eliminate the emission of alternating magnetic or electric fields strengths have been made. The terminal was used for all kinds of emission except that of the electrostatic field strength, which was eliminated by a metal screen in front of the terminal. This shielding net also decreased the alternating magnetic field strengths at the test system. The agar plates were situated horizontally without lids $62 \mathrm{~mm}$ from the front glass of the terminal. 
An approximately homogeneous electrostatic field was generated between a pair of metal plates, $0.5 \times$ $0.7 \mathrm{~m}$, at a distance of $62 \mathrm{~mm}$. The upper plate was connected to the high voltage generator in a black and white television set, and the lower one was grounded. Since the agar was molded into insulating petri dishes, the potential of the exposed agar must be defined by a ground path to the lower plate. The grounding was done through a short, conveniently bent metal wire. The agar plates were situated horizontally without lids above the lower metal plate. In this parallel plate system, the electrostatic field strengths at the surfaces of the exposed agar plates were about $250 \mathrm{kV} / \mathrm{m}$.

Twenty-one TA 100 plates were used; 13 between the metal plates in the electrostatic field, three under the terminal without electrostatic field strength, and five as exposed controls at different sites in the room. The experiment was run twice and the agar plates were counted blind. To permit blind counting, grounding wire impressions were made on all the agar plates. Because of the possibility of a bacterial contamination from the use of metal wires (though they were handled sterile), we had three sterile control plates with nutrition agar; two between the metal plates and one under the terminal. During the experiment $(6 \mathrm{~h})$ the air temperature in the room was $14-18^{\circ} \mathrm{C}$, and the indoor air humidity was $16-20 \%$.

The number of revertants per plate were counted after the plates had been incubated at $37^{\circ} \mathrm{C}$ for $48 \mathrm{~h}$. The mean number of revertants for the exposed and control plates were estimated separately for each of the two experiments. A doubling of the number of spontaneous revertants was considered to show a mutagenic effect, according to Ames et al (1).

\section{Results}

The results are shown in table 1 . None of the three sterile plates showed more than 10 revertants in the two experiments, and thus we excluded them from the counting. The exposed plates showed fewer revertants than the controls. Thus, we did not find any significant mutagenic effect in this test system, either from the electrostatic field strength or from the video display terminal without an electrostatic field strength.

Table 1. Mutagenic activity of radiation from a video display terminal (VDT) in Salmonella strain TA 100 used in the Ames test. The test is considered to be positive when the ratio revertants per exposed plate: revertants per control plate is greater than $2 .^{a}$

\begin{tabular}{|c|c|c|c|c|}
\hline & \multicolumn{4}{|c|}{ Revertants } \\
\hline & \multicolumn{2}{|c|}{ Experiment 1} & \multicolumn{2}{|c|}{ Experiment 2} \\
\hline & Mean & $\mathrm{SD}$ & Mean & $\mathrm{SD}$ \\
\hline $\begin{array}{l}\text { VDT } \\
\text { Electrostatic field } \\
\text { Controls }\end{array}$ & $\begin{array}{r}92 \\
99 \\
100\end{array}$ & $\begin{array}{r}7 \\
14 \\
8\end{array}$ & $\begin{array}{l}91 \\
72 \\
93\end{array}$ & $\begin{array}{r}20 \\
6 \\
21\end{array}$ \\
\hline
\end{tabular}

a The ratio exposed: controls was less than 1 for all the experimental situations.

\section{Discussion}

In this study it has been shown that no mutagenic effects, as detected by the Ames test, occur in front of a video display terminal or in exposure to electrostatic field strengths. The distance from the terminal was very short $(62 \mathrm{~mm})$, and the field strengths very high $(250 \mathrm{kV} / \mathrm{m})$, as compared to those of a common work situation at a terminal. The normal work distance at a terminal is in the range of $0.5-0.8 \mathrm{~m}$ from the screen. On a very cold and dry winter day the electrostatic field strength observed at this distance is no more than $20 \mathrm{kV} / \mathrm{m}$ (2).

The absence of any mutagenic effects, as detected by the Ames test system, does not support the claims that work with video display terminals is associated with risks of skin cancer. However, this study does not provide information about other kinds of side effects, ie, eye and skin symptoms and possible teratogenic effects. The Ames test also covers only one type of genotoxic effect.

The Ames test is a biological test which has been constructed for the rapid detection of the possibility of mutagenic effects and is used, for example, for testing chemicals, foodstuffs, and physical effects $(6$, $9,12)$. Thus the Ames test would reasonably respond to exposure in a time span (here $6 \mathrm{~h}$ ) which is very short in comparison to VDT operators' accumulated worktime at a terminal. We believe that this mutagenicity study supports the view that there is no increased risk of skin cancer associated with work at video display terminals.

\section{Acknowledgments}

We are very grateful to Mrs S Gustafsson and Mrs M Ståhlberg from the National Institute of Environmental Medicine, Stockholm, for their skilled technical assistance.

\section{References}

1. Ames BN, McCann J, Yamasaki E. Methods for detecting carcinogens and mutagens with the Salmonella/ mammalian-microsome mutagenicity test. Mutat Res 31 (1975) 347-364.

2. Berg M, Langlet I. Defective video display shields and skin problems. Lancet 1 (1987) 800. (Letter to the editor).

3. Cato Olsen W. Electric field enhanced aerosol exposure in visual display terminal environments. Christian Mickelsen Institute, Department of Science and Technology, Bergen (Norway) 1981.

4. Feldman L, Eaglstein W. Terminal illness. J Am Acad Dermatol 12 (1985) 366. (Letter to the editor).

5. Frank AL. Effects on health following occupational exposure to video display terminals (40536-0084). Department of Preventive Medicine and Environmental Health, University of Kentucky, Lexington, KY 1983.

6. Isildar M, King RD, Bakale G. Mutagenic response of Ames salmonella tester strain to ionizing radiation. In: Thirty-first annual meeting of the Radiation Research Society, 1983, San Antonio, Texas, USA, p 145. (Meeting abstract).

7. Lidén C, Wahlberg JE. Work with video display terminals among office employees. Scand J Work 
Environ Health 11 (1985) 489-493.

8. Lidén $\mathrm{C}$, Wahlberg JE. Does visual display terminal work provoke rosacea? Contact Dermatitis 13 (1985) $235-241$.

9. Lindelöf B, Forslind B, Victorin K. Mutagenic response of the Ames salmonella tester strain (TA 100) to different types of electromagnetic radiation used in dermatological therapy. Photodermatology 4 (1987) 49-51.

10. Lindén V, Rolfsen S. Video computer terminals and occupational dermatitis. Scand J Work Environ Health 7 (1981) 62-64. (Letter to the editor).

11. Murray WE, Moss CE, Parr WH, Cos C, Smith MJ, Cohen BFG, Stammerjohn LW, Happ A. Potential health hazard of video display terminals. Public Health Service, National Institute for Occupational Safety and Health, Cincinnati, OH 1981. (Research report 81-129).

12. Nakano E, Ichikawa-Ryo H, Kondo S. Comparative mutability of the Ames tester strains of salmonella thyphimurium by ultraviolet radiation and by 4 -nitroquinoline 1-oxide. Mutat Res 93 (1982) 35-44.

13. Paulsen L-E, Kristiansson I, Malmström I. Strålning från dataskärmar [Radiation from visual display terminals]. National Institute of Radiation Protection, Stockholm 1984. (Report no 84-08).

14. Rycroft RJG, Calnan CD. Facial rashes among visual display unit operators. In: Pearce BG, ed. Health hazards of VDTs? John Wiley \& Sons, Chichester 1984, pp 13-15.

15. Stenberg B. A Rosacea-like skin rash in VDU-operators. In: Knave B, Widebäck P-G, ed. Selected papers from the international scientific conference: Work with display units, Stockholm 12-15 May 1986. North-Holland, Elsevier Science Publishers BV, Amsterdam 1987, pp $160-164$.

Received for publication: 28 September 1987 